Proc. Indian Acad. Sci. (Chem. Sci.), Vol. 89, Number 2, April 1980, pp. 175-181.

(C) Printed in India.

\title{
Nonrigid molecular behaviour of beryllium borohydride I. INDO study
}

\begin{abstract}
CARL TRINDLE* and SAMBHU N DATTA
*Department of Chemistry, University of Virginia, Charlottesville Va 22901, USA Department of Chemistry, Indian Institute of Technology, Powai, Bombay 400 007, India

MS received 6 November 1979; revised 16 January 1980

Abstract. Potential barriers of internal motions in three different structures of beryllium borohydride have been calculated by the INDO method. INDO results show that only two structures can be optimised along the path of interconversion.
\end{abstract}

Keywords. Internal motion; potential barrier; INDO ; beryllium borohydride.

\section{Introduction}

The structure of beryllium borohydride has been a puzzle to the chemists from time to time. Available experimental data indicate the presence of more than one structure undergoing rapid interconversions among themselves (Almerningen et al 1967; Burg and Schlesinger 1940 ; Cook and Morgan 1969; Marynick and Lipscomb 1971, 1972; Nibler 1972; Silbiger and Bauer 1946; Stosick 1952; Nibler and Mcnabb 1969; Nibler and Dyke 1970). Ab initio Hartree-Fock Self-Consistent-Field Configuration-Interaction (HFSCF/CI) studies by Marynick and Lipscomb (1973) show that three possible structures may coexist and undergo a rapid intermolecular hydrogen tautomerism. These three structures belong to the $D_{2 d}$, $C_{8}$ and $D_{3 a}$ point group symmetry, the second one being primarily responsible for the observed dipole moment of $2 \cdot 1 D$ (Nibler and McNabb 1969; Nibler and Dyke 1970).

If beryllium borohydride is to be considered as a fluxional molecule, a permutational group-theoretical analysis using the notion of proper generators (Trindle and Bouman 1975) may be carried out in order to evaluate the properties of the system. Such a study requires the knowledge of potential barriers to various internal motions, and interconversions among different possible structures. In this work we report the INDO results for these potential barriers.

\section{Calculations}

We choose the three optimised structures of Marynick and Lipscomb (1973) and call the $D_{2 d}, C_{8}$ and $D_{3 \phi}$ structures as structures 1,2 and 3 . We investigate the 
following internal motions: (i) Internal rotations of $\mathrm{H}_{2}^{t} \mathrm{~B},-\mathrm{BH}_{2}^{b} \mathrm{Be}-$ and $\mathrm{H}_{2}^{t} \mathrm{BH}{ }_{2}^{3} \mathrm{Be}-$ groupings in structures 1 and 2 and of $\mathrm{H}^{t}-\mathrm{BH}_{3}^{b} \mathrm{Be}$ group of structure 3 ; (ii) $(3,6)$ permutations and simultaneous $(3,6),(4,5)$ permutations of hydrogens in structure $1,(3,6)$ permutation in structure 2 and $(3,7)$ permutation in structure 3. More simultaneous multiple permutations are not considered since the potential barriers in single and double pair permutations in structure 1 turn out to be nearly equal and quite high so that these motions may not significantly contribute to the non-rigidity of the species. The structures 1,2 and 3 are shown in figure 1 .

Since structure 2 appears as a stable intermediate between structures 1 and 3 we investigate only 1-2 and 2-3 interconversions. The paths of these interconversions are chosen in accordance with the McIver-Stanton symmetry rules (McIver and Stanton 1972; Stanton and McIver 1975) and are shown in figure 1.

\section{Discussion}

We show the relative stabilities of the three structures in table 1a. Although the INDO results show a reverse order of stability, the trend is quite inconclusive since .all the three structures are comparable in stability. Table $1 \mathrm{~b}$ shows the valence orbital energies for the three structures. The lowest virtual orbital in the $D_{2 s}$ structure degenerates giving rise to the possibility of the existence of a low-lying Jahn-Teller excited state of distorted molecular symmetry which may contribuite to the ground state dipole moment.

The potential barriers in various internal rotations and permutations are shown in table 2. Most of the processes involve high energy barriers and are not expected to contribute to the non-rigidity of the species. Internal rotations of the $\mathrm{H}_{2}^{t} \mathrm{BH} \mathrm{H}_{2}^{b} \mathrm{Bo}-$ group in structure 2 and that of the $\mathrm{H}^{t} \mathrm{BH}_{3}^{b} \mathrm{Be}$ group in structure 3 are associated with relatively small barriers. These motions are important in determining the flexibility of each individual structure.

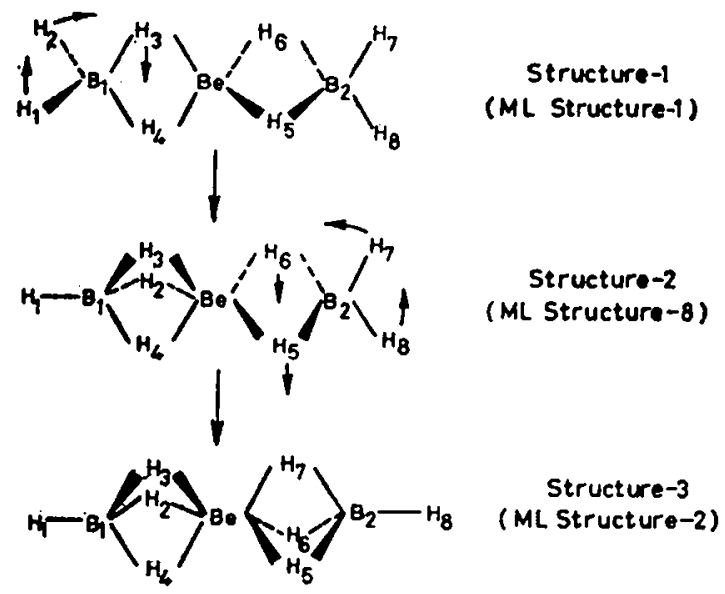

Figure 1. Structures of beryllium borohydride and the interconversion routes. 
Table 1a. Relative energies of the structures of beryllium borohydride.

\begin{tabular}{ccc}
\hline \multirow{2}{*}{ Structure } & \multicolumn{2}{c}{$\begin{array}{c}\text { Relative energy in } \\
\text { kcal, moi-1 }\end{array}$} \\
\cline { 2 - 3 } & $\begin{array}{c}\text { INDO } \\
\text { calculation }\end{array}$ & $\begin{array}{c}\text { Ab initiol } \\
\text { CI* }^{*}\end{array}$ \\
1 & 0.00 & 0.00 \\
2 & -33.67 & 6.5 \\
3 & -76.62 & 7.3 \\
\hline
\end{tabular}

* From Merynick and Lipscomb (1973).

Table 1b. INDO valence orbital energies for the structures of beryllium borohydride.

\begin{tabular}{|c|c|c|c|c|c|}
\hline \multicolumn{2}{|c|}{ Structure 1} & \multicolumn{2}{|c|}{ Structure 2} & \multicolumn{2}{|c|}{ Structure 3} \\
\hline$D_{2 d}$ & A.u. & $C_{s}$ & A.u. & $D_{3 d}$ & A.u. \\
\hline$A_{1}$ & $-1 \cdot 3621$ & $A^{\prime}$ & $-1 \cdot 3975$ & $A_{l_{a}}$ & $-1 \cdot 4198$ \\
\hline$B_{1}$ & $-1 \cdot 2513$ & $A^{\prime}$ & $-1 \cdot 2532$ & $A_{\mathbf{2}_{u}}$ & $-1 \cdot 2669$ \\
\hline$E$ & $-0 \cdot 7934$ & $A^{\prime \prime}$ & -0.8516 & $E_{u}$ & -0.8387 \\
\hline$A_{!}$ & -0.7345 & $A^{\prime}$ & -0.7864 & $A_{k_{y}}$ & $-0 \cdot 7344$ \\
\hline $\overrightarrow{B_{1}}$ & -0.6587 & $A^{\prime}$ & -0.7385 & $A_{2 u}$ & -0.6645 \\
\hline$E$ & -0.6372 & $A^{\prime}$ & -0.6538 & $E_{a}$ & -0.5920 \\
\hline$E$ & 0.2596 & $A^{\prime}$ & -0.6291 & $A_{1_{o}}$ & 0.1878 \\
\hline$A_{1}$ & $0 \cdot 1890$ & $A^{\prime \prime}$ & -0.5891 & $E_{\omega}$ & $0 \cdot 2206$ \\
\hline & & $A^{\prime}$ & $0 \cdot 1492$ & & \\
\hline & & $A^{\prime}$ & $0 \cdot 1845$ & & \\
\hline & & $A^{\prime}$ & 0.2200 & & \\
\hline
\end{tabular}

Table 1c. Choice of INDO parameters.

\begin{tabular}{|c|c|c|c|}
\hline & $\mathbf{H}$ & $\mathbf{B e}$ & $\mathbf{B}$ \\
\hline$-\beta_{\lambda}^{0}(\mathrm{eV})$ & 9 & 13 & 17 \\
\hline$G^{1}(\mathrm{Au})$ & $\cdots$ & $0 \cdot 1407$ & 0.199265 \\
\hline$F^{2}(\mathrm{Au})$ & $\cdots$ & $0 \cdot 089125$ & $0 \cdot 13041$ \\
\hline$Z^{\prime}($ STO exponent $)$ & $1 \cdot 2$ & $1 \cdot 95$ & $2 \cdot 6$ \\
\hline \multirow[t]{2}{*}{$\frac{1}{2}(I+A)(\mathrm{eV})$} & $13 \cdot 06(1 s)$ & $9 \cdot 32(2 s)$ & $14 \cdot 05(2 s)$ \\
\hline & & $5 \cdot 96(2 p)$ & $8 \cdot 30(2 p)$ \\
\hline
\end{tabular}

The various terms are as denoted in the reference by Pople et al (1967). 
Table 1d. Atomic coordinates in $\AA$.

\begin{tabular}{|c|c|c|c|}
\hline & $x$ & $y$ & $z$ \\
\hline & & & \\
\hline $\mathrm{H}^{t}$ & 1.0389 & 0.0 & $2 \cdot 4988$ \\
\hline $\mathbf{H}^{b}$ & 0.0 & $1 \cdot 0227$ & 1.0790 \\
\hline $\mathbf{B}$ & 0.0 & 0.0 & 1.9182 \\
\hline $\mathrm{Be}$ & 0.0 & 0.0 & 0.0 \\
\hline \multicolumn{4}{|c|}{ II. $C_{s}$} \\
\hline $\mathbf{H}^{t}$ & 0.0 & 0.0 & -2.9202 \\
\hline $\mathbf{H}^{b}$ & $1 \cdot 1529$ & $0 \cdot 0$ & $-1 \cdot 1618$ \\
\hline $\mathbf{H}^{b}$ & -0.5716 & 0.9921 & $-1 \cdot 2453$ \\
\hline $\mathbf{H}^{b}$ & -0.5716 & -0.9921 & $-1 \cdot 2453$ \\
\hline $\mathbf{H}^{t}$ & $1 \cdot 0391$ & $0 \cdot 0$ & $2 \cdot 5044$ \\
\hline $\mathbf{H}^{t}$ & -1.0391 & 0.0 & $2 \cdot 5031$ \\
\hline $\mathbf{H}^{b}$ & 0.0 & $1 \cdot 0206$ & $1 \cdot 1132$ \\
\hline $\mathrm{H}^{b}$ & 0.0 & $-1 \cdot 0206$ & $1 \cdot 1132$ \\
\hline B & $0 \cdot 0$ & $0 \cdot 0$ & 1.92227 \\
\hline B & $0 \cdot 0$ & 0.0 & -1.7436 \\
\hline $\mathrm{Be}$ & 0.0 & 0.0 & $0 \cdot 0$ \\
\hline \multicolumn{4}{|c|}{ III. $D_{3_{d}}$} \\
\hline $\mathrm{H}^{t}$ & 0.0 & $0 \cdot 0$ & 2.9217 \\
\hline $\mathbf{H}^{b}$ & $-1 \cdot 1458$ & 0.0 & $1 \cdot 2290$ \\
\hline B & 0.0 & 0.0 & 1.7437 \\
\hline $\mathrm{Be}$ & 0.0 & 0.0 & 0.0 \\
\hline
\end{tabular}

Reference : Marynick and Lipscomb (1973).

The 1-2 interconversion has a small potential barrier of $1 \cdot 132 \mathrm{kcal} \mathrm{mol}^{-1}$ with respect to structure 1 , but the $2-3$ process does not have any barrier at all. Structures 2 and 3 appear to be related by large amplitude vibrational motions. This result casts serious doubt on the geometry optimisation of Marynick and Lipscomb (1973). The conventional prosedure of geometry optimisation involves optimisation along a few symmetry coordinates without disturbing the gross symmetry of the species, thus giving rise to the possibility of overlooking optimisation along a possible interconversion path. Our calculation shows that either structure 2 or structure 3 (but not both at the same time) is to be considered as the stable isomer. After considering correlation effects (HFSCF/CI) one may choose structure 2 as the more stable configuration.

The reverse order of stability in table 1 casts serious doubt on the quantitative reliability of the INDO method in dealing with the fluxional behaviour related to the interconversion mechanism. This work uses results from a standard CNINDO program of the Quantum Chemistry Program Exchange (QCPE No. 194) of Indiana University, based on the work of Pople and co-workers (Pople et al 1965, 1967; Pople and Segal 1965, 1966). We also include the INDO parameters, the 
Table 1e. Calculated Coulomb integrals in $\AA$.

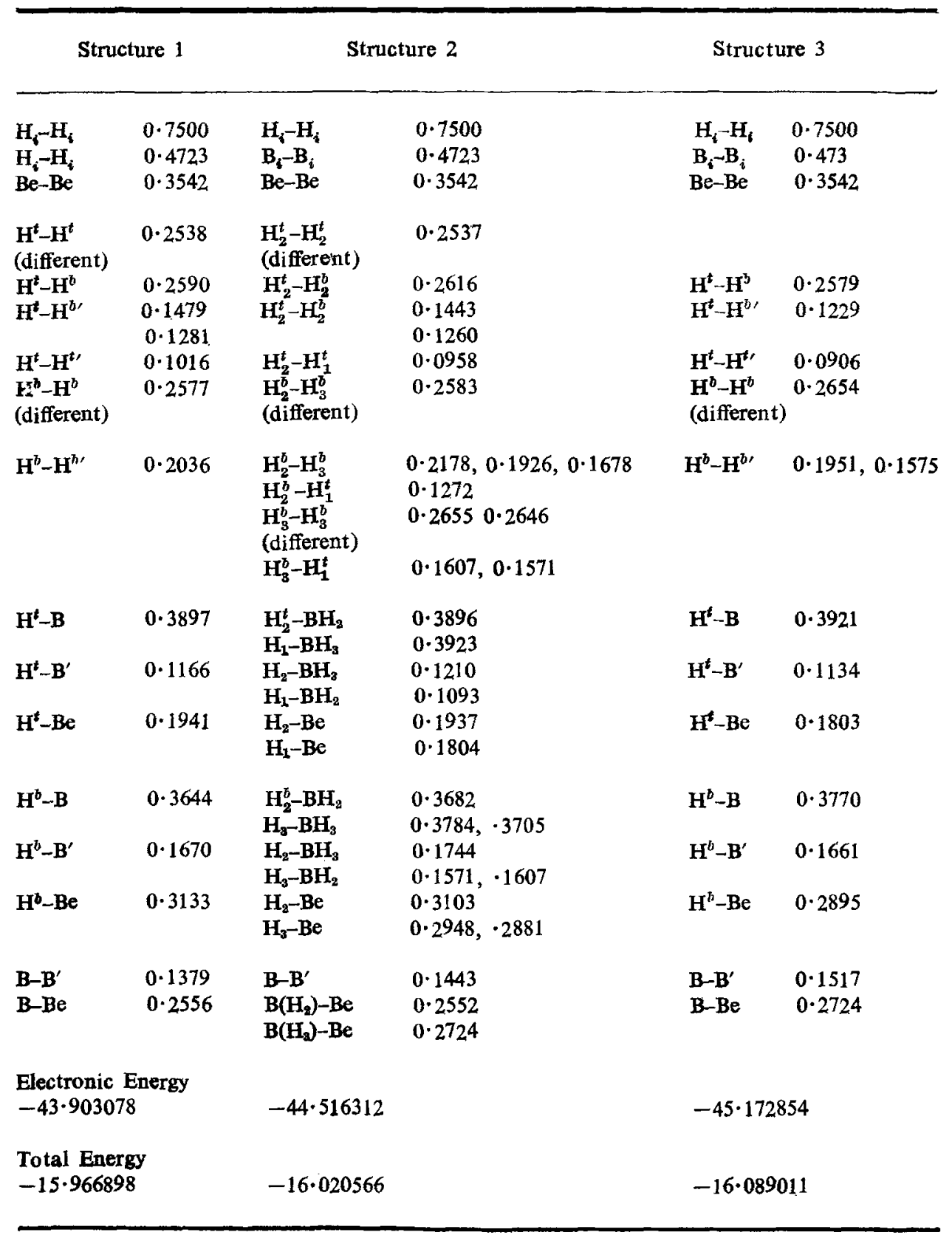

chosen coordinates and the calculated Coulomb integrals in tables 1c, $1 \mathrm{~d}$ and 1e. Because of the smallness of the related potential barriers and the presence of a low-lying empty $E_{u}$ orbital in structure 3 one does not expect an elaborate CI calculation to alter significantly the gross conclusions achieved in this work.

In summary our INDO results predict the species to be described by two interconverting isomers (structure 1 and, for example, 2) with a small potential barrier 
Table 2. INDO potential barriers of internal motions in beryllium borohydride.

Structure Internal motion $\begin{gathered}\text { Potential } \\ \text { barrier in } \\ \text { kcal. mol-1 }^{-1}\end{gathered}$

Internal rotation

$\begin{array}{llc}1 & \mathbf{H}_{2}^{t} \mathbf{B} \text { group } & 200 \cdot 8 \\ 1 & -\mathbf{B H}_{2}^{b} \mathrm{Be}-\text { grouping } & 238 \cdot 4 \\ 1 & \mathbf{H}_{2}^{t} \mathbf{B} \mathbf{H}_{2}^{b} \mathrm{Be} \text { group } & 37 \cdot 16 \\ 2 & \mathbf{H}_{2}^{t} \mathrm{~B} \text { group } & 248 \cdot 0 \\ 2 & -\mathbf{B H}_{2}^{b} \mathrm{Be}-\text { grouping } & 245 \cdot 8 \\ 2 & \mathbf{H}_{2}^{t} \mathrm{BH} \mathbf{H}_{2}^{b} \mathrm{Be} \text { group } & 2 \cdot 468 \\ 3 & \mathbf{H}^{t} \mathbf{B H}_{3}^{b} \mathrm{Be} \text { group } & 1 \cdot 875\end{array}$

\section{Permutations}

$\begin{array}{lll}1 & (3,6) & 356 \cdot 6 \\ 1 & (3,6) \text { and }(4,5) & 355 \cdot 9 \\ 2 & (3,6) & 326 \cdot 4 \\ 3 & (3,7) & 370 \cdot 0\end{array}$

\section{Interconversions}

\begin{tabular}{lll}
$1-2$ & Interconversion & $1 \cdot 132^{a}$ \\
$2-3$ & Interconversion & $\mathrm{Nil}^{b}$ \\
\hline
\end{tabular}

a Potential barrier with respect to structure 1 .

b No barrier between the two structures along this route.

in their interconversion. There is a large amplitude vibrational motion associated with the second isomer. It has also an internal rotation of comparatively small barrier. A permutational group-theoretical analysis is being published soon.

\section{Acknowledgement}

One of the authors (SND) acknowledges financial support from the University of Burdwan.

\section{References}

Almerningen A, Gnudersen G and Haaland A 1967 Chem. Commun. p 557

Burg A B and Schlesinger H I $1940 \mathrm{~J}$. Am. Chem. Soc. 623425

Cook T H and Morgan G L 1969 J. Am. Chem. Soc. 91774

Marynick D S and Lipscomb W N $1971 \mathrm{~J}$. Am. Chem. Soc. 932322

Marynick D S and Lipscomb W N 1972 Inorg. Chem. 11820

Marynick D S and Lipscomb W N $1973 \mathrm{~J}$. Am. Chem. Soc. 957244

McIver J W Jr. and Stanton R E $1972 \mathrm{~J}$. Am. Chem. Soc. 942525 
Nibler J W and McNabb W N 1969 Chem. Commun. 134

Nibler J W and Dyke T $1970 \mathrm{~J}$. Am. Chem. Soc. 922920

Nibler J W 1972 J. Am. Chem. Soc. 943349

Pople J A, Santry D P and Segal G A 1965 J. Chem, Phys, 43 S129

Pople J A and Segal G A 1965 J. Chem. Phys. 43 S136

Pople J A and Segal G A 1966 J. Chem. Phys. 443287

Pople J A, Beveridge D L and Dobosh P A 1967 J. Chem. Phys. 472026

Santry D P and Segal G A 1967 J. Chem. Phys. 47158

Silbiger G and Bauer S H $1946 \mathrm{~J}$. Am. Chem. Soc. 68312

Stanton R E and McIver J W Jr. $1975 \mathrm{~J}$. Am. Chem. Soc. 973632

Stosick A J 1952 Acta Crystallogr. 5158

Trindle C and Bouman T D 1975 Int. J. Quantum Chem. 9S 255

P. (A) -10 